\title{
Investigation of the usage of herbal products during the Covid-19 pandemic
}

\author{
Semih BULUT 1 * (D), Burcu ÖZTÜRK ŞAHİN 2 (D), Nilgün YILMAZ DEMİRCI 2 (D), \\ Didem DELIORMAN ORHAN 1 (D) \\ 1 Department of Pharmacognosy, Faculty of Pharmacy, Gazi University, Ankara, Turkey. \\ 2 Department of Chest Diseases, Faculty of Medicine, Gazi University, Ankara, Turkey. \\ * Corresponding Author. E-mail: eczsemih42@gmail.com (S.B.); Tel. +90-536-496 4641.
}

Received: 22 June 2021 / Revised: 06 September 2021/ Accepted: 07 September 2021

\begin{abstract}
During the COVID-19 pandemic period, herbal products have been used by patients for many purposes. In this study, the frequency of use of herbal products during the COVID-19 pandemic was investigated. This research is a cross-sectional study. Patients who admitted to an academic hospital (Gazi University Faculty of Medicine) Chest Diseases Clinic between November 2020-January 2021 were included in the study. It was concluded that approximately $32 \%$ of the patients used herbal products during the pandemic period and that the purpose of most of the participants was to strengthen the immune system. It was observed that the participants first consulted the spice sellers about the medicinal plants used against COVID-19. As a result, it has been determined that patients from many segments of society use herbal products against COVID-19 and they generally learn about the use of these products from nonmedical sources. In this work, as it is always emphasized in terms of human health, the importance of being the first address where physicians and pharmacists should provide consultancy services on herbal products during the COVID19 pandemic has been demonstrated once again.
\end{abstract}

KEYWORDS: Chest diseases; covid-19; herbal products; phytotherapy.

\section{INTRODUCTION}

A total of 41 cases of pneumonia of unknown etiology were detected at the end of 2019 in the city of Wuhan in Hubei Province, China [1]. On February 11, 2020, the World Health Organization (WHO) named this disease, which has become an epidemic, as the coronavirus disease (COVID-19) caused by the new coronavirus. Renamed the virus as severe acute respiratory syndrome coronavirus-2 (SARS-CoV-2) by the International Committee on Virus Taxonomy [2]. SARS-CoV-2 has spread to many countries with thousands of cases and has caused devastating health problems for people all over the world. Currently, no effective drug therapy has been found for patients infected with COVID-19 [3]. Studies on COVID-19 in Turkey started on January 10 and within the same month, Scientific Advisory Board of the Republic of Turkey Ministry of Health convened. The first COVID-19 case in Turkey was recorded on March 11, 2020. During the pandemic process, there has been an increase in the number of cases and deaths in Turkey, as in other countries [4].

The lack of treatment options for COVID-19 has raised concerns among people. Thus, there has been increased interest in preventive strategies to stop transmission of the disease or to palliate the progression of the infection. In particular, plant extracts have become an option to increase immunity and reduce the possibility of being infected with COVID-19 [5].

Herbal products have been used in many health problems such as allergies, arthritis, pain, weakness, gastrointestinal problems, infections, wounds and burns throughout human history [6]. These products have a long history and have been used by humans to prevent and treat various epidemic diseases. Many traditional treatment methods and natural medicine or raw materials have been utilized for severe acute respiratory syndrome (SARS). However, perspectives on the uses of herbal products to prevent and treat COVID-19 are an uncertain and debatable issue in many countries [7].

People use many herbal products believing that they are safe. If physicians do not question the use of herbal products by patients, a history of herbal product use cannot be revealed. Patients rarely inform the physician because of their incorrect assumption that herbal products are always harmless and safe [8].

How to cite this article: Bulut S, Öztürk Şahin B, Yılmaz Demirci N, Deliorman Orhan D. Investigation of the usage of herbal products during the Covid-19 pandemic. J Res Pharm. 2021; 25(6): 913-919. 
Inadequate quality control analysis of herbal products, inappropriate storage conditions and inaccuracy of information make questionable for their safety of these products $[9,10]$.

There has been no scientific data on the behaviours on use of herbal products for patients during the Covid-19 pandemic in Turkey until now. In this study, the main object is to investigate the attitudes and behaviors concerning herbal product use of patients who applied to the Chest Disease Outpatient Clinic during the COVID-19 pandemic.

\section{RESULTS}

A total of 152 patients admitted to the Chest Diseases Clinic participated in this study. Of the patients, $52 \%(n=79)$ were male and $48 \%(n=73)$ were female. The majority $(29.6 \%)$ of the patients were between the ages of 30 and 44 . Most of the patients (73\%) were married. In addition, more than half of the patients $(58.6 \%)$ did not have a chronic disease. Demographic characteristics of the patients are shown in Table 1.

Table 1. Demographic characteristics of the patients.

\begin{tabular}{lll}
\hline $\begin{array}{l}\text { Demographic } \\
\text { features }\end{array}$ & $\mathbf{n}$ (number) & \% (percent) \\
\hline $\begin{array}{l}\text { Gender } \\
\text { Male }\end{array}$ & 79 & 52.0 \\
Famale & 73 & 48.0 \\
Year & & \\
$18-29$ & 33 & 21.7 \\
$30-44$ & 45 & 29.6 \\
$45-59$ & 38 & 25.0 \\
$60-74$ & 29 & 19.1 \\
$\geq 75$ & 7 & 4.6 \\
& & \\
Marital status & & 73.0 \\
Married & 111 & 27.0 \\
Single & 41 & \\
& & \\
Chronic & & 58.6 \\
disease & & 41.4 \\
No & 89 & 100.0 \\
Yes & 63 & \\
Total & 152 & \\
\hline
\end{tabular}

Most of the participants were graduated from university (36.2\%) and high school (25.7\%). Among the participants, $40 \%$ of university graduates and $33.3 \%$ of high school graduates stated that they use herbal products for COVID-19 disease. The use of herbal products against COVID-19 according to the education level of the patients is shown in Table 2.

Table 2. The use of herbal products against COVID-19 with respect to the educational level of the patients.

\begin{tabular}{|c|c|c|c|c|}
\hline \multirow[t]{2}{*}{ Education } & \multicolumn{3}{|c|}{$\begin{array}{l}\text { Herbal product usage } \\
\text { status }\end{array}$} & \multirow{2}{*}{$\begin{array}{l}\text { P value } \\
0,572\end{array}$} \\
\hline & Yes (n; \%) & No (n; \%) & Total & \\
\hline No formal Education & $1 ; 33.3$ & $2 ; 66.7$ & $3 ; 2.0$ & \\
\hline Primary school education & $5 ; 25.0$ & $15 ; 75.0$ & $20 ; 13.2$ & \\
\hline Secondary school education & $5 ; 27.8$ & $13 ; 72.2$ & $18 ; 11.8$ & \\
\hline High school & $13 ; 33.3$ & $26 ; 66.7$ & $39 ; 25.7$ & \\
\hline University graduate & $22 ; 40.0$ & $33 ; 60.0$ & $55 ; 36.2$ & \\
\hline Postgraduate & $3 ; 17.6$ & $14 ; 82.4$ & $17 ; 11 ; 1$ & \\
\hline Total & $49 ; 32.2$ & $103 ; 67.8$ & $152 ; 100.0$ & \\
\hline
\end{tabular}

When smoking consumption in the COVID-19 pandemic was examined, $48 \%$ of the patients stated that they had never smoked in this period. In addition, $25 \%$ of the patients reported that they quit smoking during the COVID-19 pandemic. 
The attitudes of patients towards COVID-19 were investigated. Accordingly, 59.9\% of the patients reported that they were sometimes afraid of getting sick, $34.9 \%$ were very afraid, and $5.2 \%$ were not afraid.

Among the patients, $89(58.6 \%)$ of them stated that herbal products could be useful in preventing COVID-19 infection. The majority of these patients (98\%) used herbal product against COVID-19 infection. It was observed that patients frequently used turmeric $(20.4 \%)$, ginger $(12.2 \%)$, green tea $(10.2 \%)$, echinacea $(4.1 \%)$ and sumac $(4.1 \%)$ against COVID-19 infection. The majority of patients using herbal products stated that they preferred as tea (38.8\%) and tablet/capsule (30.6\%) forms. In this study, the reasons for patient's use of herbal products against COVID-19 was also investigated. It was determined that herbal products were preferred by $69.4 \%$ of the patients to strengthen their immunity against COVID-19 and to protect against the virus by $16.3 \%$. There was no significant difference between the gender of the patients and the purpose of using herbal products against COVID-19. The purposes of using herbal products against COVID-19 according to the gender of the patients are shown in Table 3.

Table 3. Purpose of using herbal products against COVID-19.

\begin{tabular}{lllll}
\hline Purpose of usage & Gender & & P value \\
\hline & Male $(\mathrm{n} ; \%)$ & Famale $(\mathrm{n} ; \%)$ & Total & 0,280 \\
Protect from COVID-19 & $5 ; 62.5$ & $3 ; 37.5$ & $8 ; 16.3$ & \\
Boosting immunity against COVID-19 & $14 ; 41.2$ & $20 ; 58.8$ & $34 ; 69.4$ & \\
Prevent other diseases & $1 ; 20.0$ & $4 ; 80.0$ & $5 ; 10.2$ & \\
Other reasons & - & $2 ; 100.00$ & $2 ; 4.1$ & \\
Total & $20 ; 40.1$ & $29 ; 59.1$ & $49 ; 100.0$ & \\
\hline
\end{tabular}

Another situation that is desired to be determined in the study is the duration of use of herbal products against COVID-19. It was reported that most of the patients (69.4\%) used herbal products for more than 60 days, $12.2 \%$ for $16-60$ days and $14.3 \%$ for $7-15$ days. The rate of those using herbal products for less than a week was determined as $4.1 \%$. The results of the survey showed that $30.6 \%$ of the patients used these herbal products by learning from the internet, newspaper, and television, while $28.6 \%$ used them with their personal experiences. Table 4 exerts how patients accessed information about the use of herbal products against COVID-19. It was determined that the rate of patients who reported to the physician that they used herbal products for COVID-19 was $69.4 \%$. On the other hand, it was concluded that only $8.3 \%$ of patients with any chronic disease reported the product they used against COVID-19 to the physician.

Table 4. Sources for information on the use of herbal products against COVID-19.

\begin{tabular}{ll}
\hline Information sources & $\mathbf{n ;} \%$ \\
\hline Personal experiences & $14 ; 28.6$ \\
Neighbor, friend, family & $13 ; 26.5$ \\
Social media (internet, television etc.) & $15 ; 30.6$ \\
Health professional (doctor, pharmacist) & $5 ; 10.2$ \\
Other sources & $2 ; 4.1$ \\
Total & $49 ; 100.0$ \\
\hline
\end{tabular}

When the place where the patients bought the herbal products they use against COVID-19 was investigated, it was seen that Spice Shops were preferred in the first place with a rate of $42.9 \%$. Spice shop was followed by market $(24.5 \%)$ and pharmacy $(22.4 \%)$, respectively. It was observed that $80 \%$ of secondary education graduates, $46.2 \%$ of high school graduates and $40.9 \%$ of university graduates bought herbal products from spice shops. It was revealed that more than half $(66.7 \%)$ of postgraduate-educated patients purchased herbal products against COVID-19 from the market (Table 5).

It was found that $51 \%$ of the patients who participated in the survey spent approx $€ 10$ or more and $49 \%$ of the patients spent approx $€ 10$ or less for herbal products. While the rate of those who reported the herbal products used against COVID-19 to the physician was $69.4 \%$, it was an extremely surprising result that more than half of the participants $(60 \%)$ who did not inform the physician were university graduates. At the same time, it was learned that $31.8 \%$ of university graduates learned about the products used against COVID-19 from social media and $40.9 \%$ of them bought these products from spice shops. 
Table 5. The type of retail store where the patients purchased herbal products for use against COVID-19.

\begin{tabular}{llllllll}
\hline Shop & $\begin{array}{l}\text { No- } \\
\text { education } \\
\%\end{array}$ & $\begin{array}{l}\text { Primary } \\
\text { education } \\
\%\end{array}$ & $\begin{array}{l}\text { Secondary } \\
\text { education } \\
\text { \% }\end{array}$ & $\begin{array}{l}\text { High } \\
\text { school } \\
\%\end{array}$ & $\begin{array}{l}\text { University } \\
\text { graduate } \\
\%\end{array}$ & $\begin{array}{l}\text { Post- } \\
\text { graduate } \\
\%\end{array}$ & Total \\
\hline Spice shop & - & 9.5 & 19.0 & 28.6 & 42.8 & - & 42.9 \\
Grocery & - & 8.3 & 8.3 & 8.3 & 58.3 & 16.7 & 24.5 \\
Pharmacy & 9.1 & 9.1 & - & 36.4 & 36.4 & 9.1 & 22.4 \\
Other & - & 20.0 & - & 40.0 & 40.0 & - & 10.2 \\
Total & 2.0 & 10.2 & 10.2 & 26.5 & 44.9 & 6.1 & 100.0 \\
\hline
\end{tabular}

\section{DISCUSSION}

Plants have been used for centuries in many parts of the world to treat diseases and for preventive purposes [11]. About $80 \%$ of the population in the world rely on herbal medicines for primary health care. Recently, with the increasing on use of herbal products, the issue of safety has become a public health issue [12]. Undesirable effects may occur as a result of the interaction of herbal products with drugs and foods. According to the results of the research conducted to date, it is known that the majority of those who use herbal products do not inform health professionals about the products they use [13].Since there is no drug treatment for COVID-19, traditional treatment methods commonly used in epidemics are also preferred [3]. This study is the first to investigate the use of herbal products during the COVID-19 pandemic in Turkey. In addition, this study aimed to determine the factors, usage patterns and frequency affecting herbal products use during the COVID-19 pandemic.

Alyami et al. investigated the use of herbal products during the COVID-19 pandemic. As a result of the research, it was reported that approximately $14.9 \%$ of the participants used herbal products during the COVID-19 pandemic and 7.2\% stopped using herbal products after using them for a while [5]. In our study, the rate of use of herbal products against COVID-19 was found to be higher in patients. This difference may be due to seasonal differences in the study. Demand for herbal products may have increased since our study was conducted during the winter months when upper respiratory tract infections are high. In addition, it was thought that social cultural differences and educational level differences according to the regions where the study was conducted may change the frequency of herbal product use.

Alotiby et al. studied the prevalence of using herbal products as a preventive measure during the COVID-19 pandemic. Most of the participants (92.7\%) used herbal products and 7.3\% of the participants stated that they routinely used these products before the COVID-19 pandemic. The difference between those who used herbal products before and during the COVID-19 pandemic was found to be significant [14]. The results displayed that the tendency to use herbal products increased during the pandemic process. On the other hand, interestingly, it has been determined that the use of herbal products is very high in the Saudi population.

Nguyen et al. investigated herbal medicine use and attitudes towards them during the COVID-19 pandemic. During the COVID-19 pandemic, $49 \%$ of the participants stated that they benefited from herbal products and that these products were mostly used to relieve sore throat $(62.2 \%)$, cough (60.6\%), nasal congestion $(41.4 \%)$ and to reduce fever (35.7\%) [15]. Similar to this study, the results of our study also showed that the rate of herbal product use was high in the COVID-19 pandemic. These results also exerted that although there are regional sociocultural differences during the COVID-19 pandemic, interest of people in herbal products is high.

Alyami et al. stated that social media $(39.4 \%)$ had a great impact on people's preference for herbal products during the COVID-19 pandemic period. In this study, it was reported that $37.5 \%$ of the participants used herbal products in their own homes [5]. Nguyen et al. concluded that herbal products were used by being influenced by the internet $(16.1 \%)$, as a result of personal experience $(62 \%)$, or by the recommendation of friends (43\%) [15]. In the study of Alotiby et al., it was reported that herbal product usage information was learned through social media (25.2\%), family/friends (21.6\%), and personal experience $(20.3 \%)$ during the COVID-19 pandemic [14]. In the study of Hwang et al., it was deduced that the primary sources of information were the mass media $(52.4 \%)$ and the internet $(27.4 \%)$ [16]. It has been seen that media tools (printed, digital and social) are an important source of information in the use of herbal products during the COVID-19 pandemic period. Surprisingly, only $25 \%$ of the participants consulted a doctor for this condition, and $18 \%$ asked advice from pharmacists [17]. Similar results were seen in our study. A significant portion (30.6\%) of patients using herbal products against COVID-19 learned their usage information from social media. While the rate of those who use these products with their personal experiences is $28.6 \%$, the rate of those who seek 
advice from their family/friends/neighbors is $26.5 \%$. These results showed that social media is important in the COVID-19 pandemic period. Especially in our study, only $10.2 \%$ of the patients consulted health professionals. As a conclusion, it has been seen once again how effective the information given by non-experts on social media is on people.

Nguyen et al. reported that during the pandemic period, people obtained most of the medicinal plants from their own gardens. Markets and supermarkets followed this [15]. Unlike other studies, the majority of the participants in our study purchased herbal products from spice shops. This was followed by the market $(24.5 \%)$ and the pharmacy $(22.4 \%)$. It was observed that the patients mostly did not buy herbal products from the pharmacy. In this study, we found that patients with high education levels often bought herbal products from spice shops. Most of the university graduate patients (60\%) did not inform the physician about the herbal product they used against COVID-19. Patients with a high level of education may have low health literacy. In addition, it would not be wrong to think that there may be problems in the quality standards of products not purchased from pharmacies and that these herbal products may be harmful to public health. Generally, patients do not inform the physician when using herbal products, thinking that they are harmless. This perception ignores the side effects and drug interactions associated with plants [18]. In this study, most of the patients with chronic diseases $(91.7 \%)$ did not inform the physician about the product they used against COVID-19. This result suggested that it is necessary to evaluate whether there are undesirable interactions between the drugs used by the participants and the herbal products.

In our study, we observed that the majority of patients (69.4\%) used herbal products against COVID-19 for more than two months. It was observed that the plants used by the patients were mostly turmeric $(20.4 \%)$ and ginger (12.2\%). In fact, it is desirable to use turmeric and ginger for no longer than 2 weeks [19, 20]. Echinacea should not be used for more than 1 week [21]. Similarly, if the symptoms persist for more than 1 week during the use of green tea, a doctor should be consulted [22]. For this reason, it is extremely dangerous for patients to use these products for such a long time and uncontrolled. Gastrointestinal problems have been observed as an adverse reaction after high doses and long-term use of turmeric. It has been observed that ginger can cause hypersensitivity reactions. High doses of ginger may cause central nervous system depression and cardiac arrhythmias. Intensive use of green tea has resulted in adverse effects such as excessive acidity, stomach irritation, decreased appetite, constipation or diarrhea. Adverse reactions such as rashes, facial swelling, breathing difficulties, dizziness and hypotension have been observed as a result of the use of preparations containing echinacea [23].

Hwang et al. investigated the reasons why patients used complementary methods in treatment during the 2015 MERS epidemic. It was seen that the use of these methods to improve the immune system was in the first place (63.1\%) [16]. Most of the patients stated that they used herbal products to strengthen the immune system against COVID-19. It has been reported that herbal products increase immunity and show antiviral effects during the COVID-19 pandemic [24]. Many herbs such as turmeric, echinacea, ginger, tea, black pepper, sumac, carob, vinegar, and garlic can contribute to the immune system due to their strong antioxidant activities. The anti-inflammatory effects of these plants will also have positive effects on the immune system.

Herbal products should be consumed under the recommendation and control of a physician. Long-term use of herbal products and overdoses can cause permanent damage to the body [4]. Concomitant use of herbal products with allopathic medicines may result in unknown drug-herb interactions. Adverse events may occur as a result of interaction [25, 26]. Turmeric can increase the effect of anticoagulants, so it should not be used with anticoagulants in high doses (15 g/day) [27]. Ginger has an antithrombotic effect. Patients who use anticoagulants or have bleeding disorders should avoid the use of ginger. During the use of green tea, the absorption of alkaline drugs may be delayed due to chemical bonding with tannins. Echinacea may interact with medications that have immunostimulating or immunosuppressive effects. Echinacea should not be used with cyclosporine. Echinacea may also alter the chemotherapeutic effect of corticosteroids [23]. Patients with chronic autoimmune disease should not use echinacea [27]. In addition, the metabolism of the mentioned herbal products may be different in chronic renal failure and may reach toxic levels [28].

\section{CONCLUSION}

As a result, herbal products have been used by many patients during the COVID-19 pandemic process. Information on the use of herbal products has generally been obtained from non-medical sources. As a result of this study, it was revealed that patients from all parts of society often buy herbal products from spice shops, and patients with chronic diseases do not inform the physician about the herbal products they use against COVID-19. For this reason, it has once again emerged how important it is for physicians to question their 
patients' herbal product usage information. Health professionals should provide counseling services about herbal products to patients during the COVID-19 pandemic. In addition, the Ministry of Health should follow closely the herbal products advertised on the internet and television.

\section{MATERIALS AND METHODS}

This research is a cross-sectional study. The patients who registered to Gazi University Faculty of Medicine Chest Diseases Polyclinic between 12.11.2020-12.1.2021 were included in the study. The research group consisted of adult patients. The informed consent was obtained from the those who agreed participate in the study. This study was approved by the Ethics Commission of Gazi University (Project identification code 2020-566). A hundred and fifty-two patients participated in this study. Questionnaire forms were used to obtain the research data. The questionnaire was examined in linguistic and interpretive terms validated. Questionnaires were administered face to face by the researchers. The questionnaires consisted of 21 questions, multiple-choice and open-ended. The first part included questiones for demographic information such as sex, age, education and income. The second part is aimed to determine the factors affecting the use of herbal products against COVID-19 infection by patients. The descriptive statistics were represented with frequencies and percentages. The association among categorical variables was investigated by the Chi-Square test. A value of $p<0.05$ was considered statistically significant. All reported $p$-values were two-sided. All analysis was performed by using IBM SPSS Statistics Software version 23 (IBM Corp, Armonk, NY, USA).

\section{Acknowledgements: -}

Author contributions: Concept - S.B., N.Y.D., D.D.O.; Design - S.B., N.Y.D., D.D.O.; Supervision - S.B., D.D.O., N.Y.D.; Resources - S.B., B.Ö.Ş., D.D.O.; Materials - S.B., B.Ö.Ş.; Data Collection and/or Processing - N.Y.D., B.Ö.Ş., S.B.; Analysis and/or Interpretation - S.B., N.Y.D., D.D.O., B.Ö.Ş.; Literature Search - S.B., N.Y.D; Writing - S.B., D.D.O.; Critical Reviews - S.B., D.D.O., N.Y.D., B.Ö.Ş.

Conflict of interest statement: The authors declare no conflict of interest.

Ethics commission approval: This study was approved by the Ethics Commission of Gazi University (Project identification code 2020-566).

\section{REFERENCES}

[1] Lu H, Stratton CW, Tang YW. Outbreak of pneumonia of unknown etiology in Wuhan, China: the mystery and the miracle. J Med Virol. 2020; 92(4): 401-402. [CrossRef]

[2] Lai CC, Shih TP, Ko WC, Tang HJ, Hsueh PR. Severe acute respiratory syndrome coronavirus 2 (SARS-CoV-2) and coronavirus disease-2019 (COVID-19): The epidemic and the challenges. Int J Antimicrob Agents. 2020; 55(3): 105924. [CrossRef]

[3] Zhang ZJ, Wu WY, Hou JJ, Zhang LL, Li FF, Gao L, Wu XD, Shi JY, Zhang R, Long HL, Lei M, Wu WY, Guo DA, Chen KX, Hofmann LA, Ci ZH. Active constituents and mechanisms of Respiratory Detox Shot, a traditional Chinese medicine prescription, for COVID-19 control and prevention: Network-molecular docking-LC-MSE analysis. J Integr Med. 2020; 18(3): 229-241. [CrossRef]

[4] Türkiye Bilimler Akademisi. Covid-19 pandemi değerlendirme raporu. Ankara, 17 Nisan 2020.

[5] Alyami HS, Orabi MAA, Aldhabbah FM, Alturki HN, Aburas WI, Alfayez AI, Alharbi AS, Almasuood RA, Alsuhaibani NA. Knowledge about COVID-19 and beliefs about and use of herbal products during the COVID-19 pandemic: A cross-sectional study in Saudi Arabia. Saudi Pharm J. 2020; 28(11): 1326-1332. [CrossRef]

[6] Dada R, Sabharwal P, Sharma A, Henkel R. Use of herbal medicine as primary or supplementary treatments. In: Henkel R, Agarwal A. (Eds). Herbal Medicine in Andrology. Academic Press, Elsevier Inc., Cambridge, 2021, pp.915. [CrossRef]

[7] Xiong Y, Gao M, van Duijn B, Choi H, van Horssen F, Wang M. International policies and challenges on the legalization of traditional medicine/herbal medicines in the fight against COVID-19. Pharmacol Res. 2021; 166: 105472. [CrossRef]

[8] Setty AR, Sigal LH. Herbal medications commonly used in the practice of rheumatology: mechanisms of action, efficacy, and side effects. Semin Arthritis Rheum. 2005; 34(6): 773-784. [CrossRef] 
[9] Ekor M. The growing use of herbal medicines: issues relating to adverse reactions and challenges in monitoring safety. Front Pharmacol. 2014; 4: 177. [CrossRef]

[10] Koshak AE. Attitudes and beliefs towards herbal medicines in patients with allergic diseases: A pilot survey study in Western Saudi Arabia. J Herb Med. 2021; 25: 100413. [CrossRef]

[11] Li FS, Weng JK. Demystifying traditional herbal medicine with modern approach. Nat Plants. $2017 ; 3$ : 17109. [CrossRef]

[12] Woo CSJ, Lau JSH, El-Nezami H. (2012). Herbal medicine: toxicity and recent trends in assessing their potential toxic effects. Adv Bot Res. 2012; 62: 365-384. [CrossRef]

[13] Uzun MB, Aykaç G, Özçelikay G. Bitkisel ürünlerin yanlış kullanımı ve zararları. Lokman Hekim Derg. 2014; 4(3): 15.

[14] Alotiby AA, Al-Harbi LN. Prevalence of using herbs and natural products as a protective measure during the COVID19 pandemic among the Saudi population: an online cross-sectional survey. Saudi Pharm J. 2021; 29(5): 410-417. [CrossRef]

[15] Nguyen PH, Tran VD, Pham DT, Dao TNP, Dewey RS. Use of and attitudes towards herbal medicine during the COVID-19 pandemic: A cross-sectional study in Vietnam. Eur J Integr Med. 2021; 44: 101328. [CrossRef]

[16] Hwang JH, Cho HJ, Im HB, Jung YS, Choi SJ, Han D. Complementary and alternative medicine use among outpatients during the 2015 MERS outbreak in South Korea: a cross-sectional study. BMC Complement Altern Med. 2020; 20: 147. [CrossRef]

[17] Ahmed I, Hasan M, Akter R, Sarkar BK, Rahman M, Sarker MS, Samad MA. Behavioral preventive measures and the use of medicines and herbal products among the public in response to Covid-19 in Bangladesh: A cross-sectional study. PloS one. 2020; 15(12): e0243706. [CrossRef]

[18] Islamoglu MS, Uysal BB, Yavuzer S, Cengiz M. Does the use of herbal medicine affect adherence to medication-a cross sectional study of outpatients with chronic disease? Eur J Integr Med. 2021; 44: 101326. [CrossRef]

[19] EMA (European Medicines Agency). https://www.ema.europa.eu/en/documents/herbal-monograph/finaleuropean-union-herbal-monograph-curcuma-longa-l-rhizoma-revision-1_en.pdf (accessed on 6 June 2021).

[20] EMA (European Medicines Agency). https://www.ema.europa.eu/en/documents/herbal-monograph/finalcommunity-herbal-monograph-zingiber-officinale-roscoe-rhizoma_en.pdf (accessed on 7 June 2021).

[21] EMA (European Medicines Agency). https://www.ema.europa.eu/en/documents/herbal-monograph/finaleuropean-union-herbal-monograph-echinacea-purpurea-l-moench-herba-recens_en.pdf (accessed on 2 August 2021).

[22] EMA (European Medicines Agency). https://www.ema.europa.eu/en/documents/herbal-monograph/finalcommunity-herbal-monograph-camellia-sinensis-l-kuntze-non-fermentatum-folium_en.pdf (accessed on 2 August 2021).

[23] Pdr for Herbal Medicines, Medical Economics Company, 2000; ISBN: 1-56363-361-2.

[24] Alami AE, Fattah A, Chait A. (2020). Medicinal plants used for the prevention purposes during the covid-19 pandemic in Morocco. J Anal Sci Appl. 2020; 2(1): 4-11. [CrossRef]

[25] Charan J, Bhardwaj P, Dutta S, Kaur R, Bist SK, Detha MD, Kanchan T, Yadav D, Mitra P, Sharma P. (2021). Use of complementary and alternative medicine (CAM) and home remedies by COVID-19 patients: a telephonic survey. Indian J Clin Biochem. 2021; 36(1): 108-111. [CrossRef]

[26] Toklu HZ. Pharmacovigilance of herbal medicine: herbavigilance. Adv Pharmacoepidemiol Drug Saf. $2016,5: 4$. [CrossRef]

[27] Demirezer Ö, FFD monografları tedavide kullanılan bitkiler, second ed., Mn medikal nobel, Ankara, 2011.

[28] Biçen C, Erdem E, Kaya C, Karataş A, Elver Ö, Akpolat T. Herbal product use in patients with chronic kidney disease. Turk Nephrol Dial Transplant J. 2012; 21(2): 136-140. [CrossRef] 